Marquette University

e-Publications@Marquette

Psychology Faculty Research and Publications

Psychology Department

$1-1-2007$

\title{
The Process of Seeking Treatment for Mental Health Problems
}

Stephen M. Saunders

Marquette University, stephen.saunders@marquette.edu

Nicholas W. Bowersox

Marquette University

Published version. Mental Health and Learning Disabilities Research and Practice, Vol. 4, No. 2 (2007): 99-123. DOI. C 2007 University of Huddersfield. Used with permission. 
The Process of Seeking Treatment for Mental Health Problems Stephen Saunders ${ }^{1} \&$ Nicholas Bowersox ${ }^{1}$

${ }^{1}$ Marquette University 


\title{
The Process of Seeking Treatment for Mental Health Problems
}

\author{
Stephen Saunders \& Nicholas Bowersox
}

\begin{abstract}
A model of the process of seeking treatment for mental health problems is presented that explicates much previous research in this area. A process comprising seven steps is proposed (recognize that there is a problem, decide the problem is mental health related, decide change is needed, make efforts to effect change, decide professional help is needed to effect change, decide to seek professional help, and seek help). Activities or decisions that interrupt the process, barriers encountered at each step, variations of the proposed sequence, and the experience of social support across the process are presented. Implications for improving access to treatment are proposed.
\end{abstract}

\section{Introduction}

A substantial proportion of people will experience a psychiatric illness during their lifetime (Kessler et al. 2005; Wang et al. 2005). A survey by the World Health Organization (WHO) found the highest annual rate of emotional or substance-use problems in the United States $(26.4 \%)$ and the lowest rate in Shanghai, China (4.3\%; WHO 2004). Results indicated that most of those with a mental illness did not receive professional treatment for it (WHO 2004), a recurrent finding in psychiatric epidemiology (e.g. Borges et al. 2006; Kessler et al. 2005; Naganuma et al. 2006; Wang et al. 2005).

Thus it is critical to understand how persons with mental health problems either obtain treatment, are prevented from receiving treatment, or refrain from seeking treatment. Most investigations into this area view treatment seeking as a dichotomous event: a person with a mental health problem either does or does not seek treatment. This conceptualisation is overly simplistic and, as a consequence, misleading. At the least, it is inconsistent with research showing that there is usually a multi-year delay between symptom onset and treatment seeking (e.g. Christiana et al. 2000; Kessler et al. 1998).

Based on an analysis of research findings, this paper proposes a rational model of the treatment seeking process. Treatment seeking is conceptualised as a series of steps (cf. Kadushin 1969; Mojtabai et al. 2002; Saunders 1993). A more comprehensive understanding of the steps in this process will help researchers and clinicians better appreciate the experiences of clients prior to entering treatment, the barriers encountered while seeking treatment, and important areas to target in programmes intended to improve access to treatment.

A brief review of demographic factors associated with the likelihood of 
seeking treatment for a mental health problem is presented. A detailed discussion of the steps in the proposed model follows, including the manner in which various personal and socio-cultural factors differentially affect each step. It will likewise be shown that specific barriers to treatment and social support factors are more salient at certain steps. Finally, ways in which individuals may deviate from the proposed sequence of steps and implications for improving access to mental health services are discussed.

\section{Demographic Factors Associated with Utilisation of Mental Health Services}

There are several demographic factors consistently found to be associated with the likelihood of seeking treatment for a mental illness (Kessler et al. 2005; Wang et al. 2005). Females receive more care than males, although this difference is the result of a greater use of general, medical services (versus psychiatric or other specialty mental health services). Unmarried persons tend to utilise mental health services more than married persons (Kessler et al. 2001a; Parslow \& Jorm, 2000), whereas better education and greater financial resources is associated with more treatment seeking (Alegria et al. 2002; Kessler et al. 2005; Kawakami et al. 2005). Finally, racial and ethnic groups who are historically disadvantaged have been found to be less likely to seek mental health care in studies conducted around the world (e.g. Alvidrez, 1999; Baxter et al. 2006; Smedley et al. 2003; Swartz et al. 1998).

\section{The Process of Seeking Treatment for Mental Health Problems}

The steps in the process of seeking treatment for a mental health problem are shown in Figure 1. Also shown are alternative decisions that might disrupt the process, as well some factors associated with each step. The steps represent sequential events that are dependent on each other. For most persons, each step occurs only after the previous step has been accomplished. As a result, persons who complete these steps represent increasingly limited subsets of potential mental health patients, as shown graphically in Figure 2. Variations to this sequence of steps are discussed briefly in this section and in more detail in a later section.

\section{Step 1: Problem Recognition}

The process of seeking treatment is initiated when a person recognizes that a problem exists. Until a person achieves this step, voluntary treatment seeking will not occur. Persons experiencing a mental illness who do not recognize it are often characterised as being "in denial," which involves minimisation or outright negation of the problem's negative effects or implications. Denial is the antithesis of problem recognition, but it is not the only cognitive process that might prevent problem recognition. A lack of knowledge of mental health problems in general (e.g. not understanding the symptoms of traumatic disorders) may also prevent problem recognition. 
Figure 1: Steps in Seeking Treatment for Mental Health Problems

\section{Treatment seeking process}

Mental health problem

develops

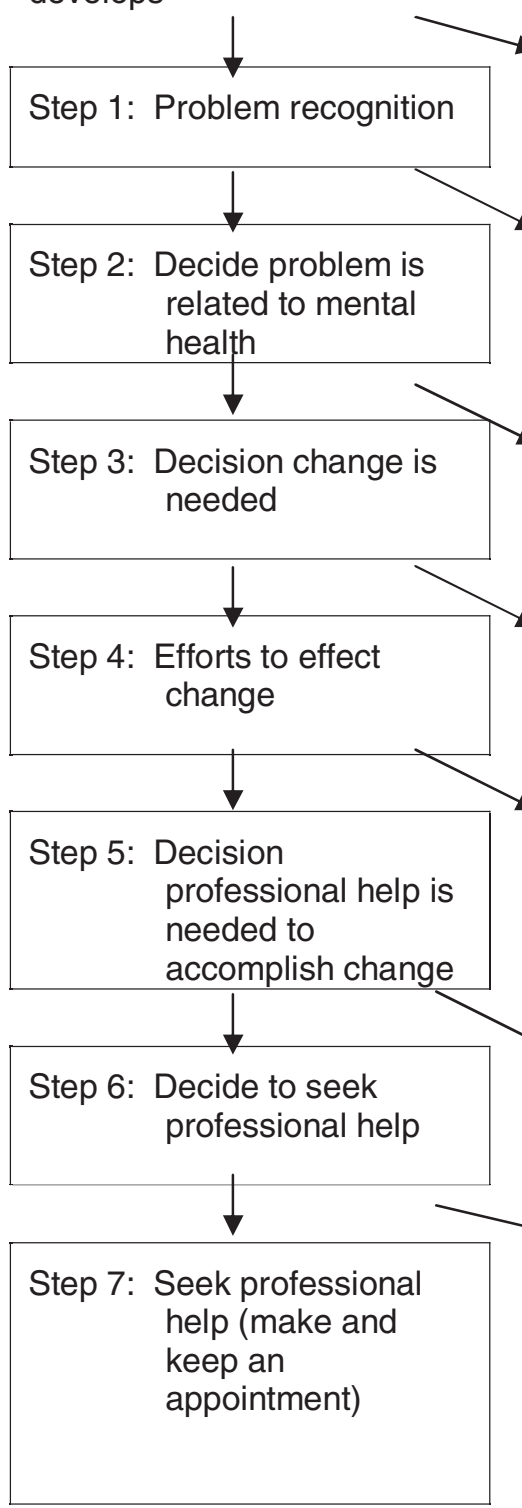

\section{Alternative decisions and actions}

Denial; Minimization; Lack of Insight; Distress; Impairment awareness

Decide problem is physical and/or situational;

Externalize responsibility

Wait; Delay change efforts Ignore problem
Ig need for chang

Continue change efforts;

Cease change efforts;

Modify efforts; Return to denial

Delay seeking help; Ongoing change efforts

Encounter insurmountable barriers; Avoid treatment; Ongoing self-change efforts; Problem resolution without professional help
Factors associated with achieving step
Vulnerability to mental illness stigma

Distress; Impairment

Social support for change; Knowledge of change strategies

Vulnerability to mental health treatment stigma; Attitude towards mental health treatment

Attitude toward treatment

Resources; External barriers
Insight; Gender;

Essential to treatment seeking, problem recognition can be a difficult and protracted process (Saunders, 1993, Veroff et al. 1981a). Generally speaking, problem recognition is more likely if the problem or illness is severe enough to cause marked distress or impairment (Goldstein et al. 2006; Israelashvili 1999; Mojtabai et al. 2002; Parslow \& Jorm, 2000). For example, a survey in the U.S. 
found that many persons who needed mental health treatment but did not get it reported that their lack of treatment occurred because they believed "the problems have not been serious enough" (Therapy in America, 2004). Mental illness is often associated with negative social, financial, medical and occupational consequences, and continued denial of a problems existence may become more difficult as such consequences become severe (George \& Tucker 1996; Hajema et al. 1999).

Research has usually not distinguished distress and impairment. Because of this, findings of a strong association between illness severity and the likelihood of treatment can be difficult to interpret (Bell et al. 1998; Kessler et al. 2005). These constructs are often grouped together under the heading of "illness severity," but it is worth understanding how distress and impairment may have different effects on treatment seeking. While elevated levels of distress motivate persons to seek care, elevated levels of impairment might actually interfere with this process. For example, occupational impairment is a common effect of mental illness (Lim et al. 2000). As such impairment worsens, it may actually become more difficult for the ill individual to seek treatment because of concerns about time and monetary constraints (Mojtabai et al. 2002). Finally, the relationship between impairment, distress, and treatment seeking is likely to be different for different disorders. For example, the intense personal distress associated with panic disorder might be a strong motivator for treatment, whereas the impairment caused by bipolar disorder might be the primary factor leading to treatment seeking.

The relationship between illness severity and treatment seeking is not entirely straightforward, however. Mental illness can cause anosognosia, or the lack of awareness of an illness. Anosognosia is most commonly associated with severe mental illness, such as schizophrenia and bipolar disorder (Jorgensen 1995; Saravanan et al. 2007), and persons with severe mental illness may thereby not seek treatment voluntarily. However, they may be brought to care involuntarily if impairment is severe enough (Goldstein et al. 2006; Parslow \& Jorm, 2000). In similar fashion, persons with alcohol use disorders may deny the existence of a problem until confronted with evidence of severe social and medical problems (George \& Tucker, 1996; Hajema et al. 1999). Even then, persons with alcohol use disorders may seek treatment only reluctantly (if at all). Such cases represent examples of a variation from the proposed process of treatment seeking, as they skip the entire process of treatment seeking except for the last step (seeking help). Research demonstrates the importance with regard to treatment effectiveness of addressing such motivational issues, as discussed in a later section.

It is important to consider that the relationship between problem severity and help-seeking may differ for various populations (Solomon, 1989). For example, research has revealed a disturbing phenomenon among adolescents wherein higher levels of suicidal ideation are associated with lower levels of mental health service utilization (Saunders et al. 1994) and help-seeking intentions (Carlton \& Deane, 2000). This may be related to underdeveloped capacity to identify, express and handle strongly negative 
emotions (Ciarrochi et al. 2003) or to a distorted sense of how their peers might handle similar situations (Israelashvili 1999).

\section{Step 2: Concluding the Problem Is Related to Mental Health}

The second step in the process is deciding that the problem is related to mental health rather than physical health or situational factors. If a mental health problem is not attributed to mental health concerns, then treatment seeking is impeded. However, attributing problems to mental illness is neither automatic nor easy, but rather happens only after other possible explanations have been exhausted (Meile \& Whitt 1981; Whitt \& Meile 1985). If a problem can be attributed to something external, then the responsibility for addressing the problem can also be externalised and potentially avoided. Mechanic and colleagues (1994) found that persons with schizophrenia who attributed their problems to mental illness rather than medical issues reported less positive social relations, lower selfesteem, and greater levels of depression. It is not difficult to understand that persons with mental illness may be reluctant to label themselves as such. Holding negative attitudes about mental illness inhibits service utilisation (Leaf et al. 1986) and diminishes treatment adherence (Scott \& Pope 2002; Sirey et al. 2001).

In other words, the issue of stigma arises at this step. Persons needing to acknowledge that a problem is due to mental illness experience disincentives to do so, related to society's "weakness/badness" assumptions about persons with mental illness. There is a general tendency to blame persons with mental illness for allowing it to develop and to continue (Brockington et al. 1993; Hamre et al. 1994). Corrigan (2004) argues that attributing a problem to mental illness arouses-in others and in oneself-stereotyped thinking about persons with mental illness (e.g. "All persons with mental illness are peculiar"), prejudiced attitudes that correspond to these stereotypes (e.g. "Persons with mental illnessincluding me-should be shunned"), and discriminatory behaviour (e.g. avoidance of persons with mental illness). With regard to self-stigma, persons who endorse this perspective with regard to mental illness are reluctant to seek treatment for themselves (Cooper et al. 2003).

Thus do persons with mental illness experience both self and social stigma not associated with physical illness (Corrigan et al. 2000; Weiner et al. 1988; Link et al. 1999). Males and young adults may be particularly reluctant to allowing a diagnosis of mental illness, as it may be perceived as a perpetual barrier to life aspirations (Sheets et al. 1982). That many persons enter mental health treatment uncertain of what a mental illness is and unconvinced that their problem is due to mental health issues is discussed later.

\section{Step 3: Deciding Change Is Necessary}

The third step comprises the determination that change is needed. This step relates to the issue of taking personal responsibility for the presence of the problem or at least responsibility for taking steps aimed at making 
the problem go away. This decision is very difficult for those who resist the idea that the problem is something to which they contribute. By this step the person has admitted that a problem exists, but he or she might nonetheless deny that change is either needed or possible. Alternatively, a person may minimize the seriousness of the problem and lessen the perceived need for treatment. Some do not engage in change efforts at all, but simply wait for the problem to go away. Kessler and colleagues (2001a) found that nearly half of persons with a serious mental illness were not receiving treatment, and about one in four reported that this was because they "thought the problem would get better by itself."

Denial that change is necessary is most classically an issue in substance use disorders (SUDs). Many persons with SUDs realize they have a problem and that the problem is due to substance use, but they do not seek treatment because they do not wish to change (Cunningham et al. 1993; Miller \& Saunders, 2007). To what extent this phenomenon pertains to persons with other mental illnesses is not clear. It seems likely, however, that deciding change is not possible is more probable in persons who have a limited understanding of mental illness and the benefits of treatment. Another potential issue is the aggressively promoted idea that mental illness is entirely the result of biological factors (i.e. "chemical imbalance"), which might suggest to some that taking personal responsibility for change is neither prudent nor necessary.

\section{Step 4: Self-Help Efforts}

Deciding that change is needed does not guarantee that a person will try to change. If they do, most initially engage in self-help efforts such as reading literature, praying, consulting non-professional help (i.e. self-help groups), or attempting to identify and change problematic behaviour (Kessler et al. 1979; Neighbors \& Jackson 1996). For example, many persons with a drinking problem attempt self-help change strategies prior to seeking professional intervention, and a good proportion resolve the problem on their own (e.g. King \& Tucker 1998; Tucker, et al. 1994). An alternative to achieving this step is continuing to wait, preparing or planning for change, or engaging in small change behaviours (Anatchkova et al. 2006). The abundance of self-help literature available to consumers suggests that many people find it useful, and there is burgeoning research suggesting that self-help products can be effective in helping persons manage their symptoms (e.g. Stice et al. 2007; Tucker \& Gladsjo 1993), although more research is needed to determine how many persons with mental illness are able to effectively do so.

\section{Step 5: Deciding Professional Treatment Is Necessary to Accomplish Change}

The next step is recognizing that professional treatment is necessary to accomplish change, perhaps because self-help efforts were inadequately successful. This is also a very difficult step, as it generates shame and stigma (Corrigan 2004; Saunders 1996). A preference for dealing with mental health problems on one's own can inhibit treatment-seeking (Ortega 
\& Alegria 2002) and, rather than admit the need for professional assistance, persons may revitalise or change their self-help strategies. At this step, attitudes towards treatment become a salient issue. Research shows that persons with mental illness are less likely to seek treatment if they believe it will not help (Meltzer et al. 2003; Therapy in America, 2004). For example, Mojtabai et al. (2002) found that respondents with positive attitudes towards treatment were 2.4 times as likely to perceive a need for help than those with less positive attitudes, and Kessler and colleagues (2001a) found that $17 \%$ of persons with serious mental illness who were not seeking needed care reported the reason that "help probably would not do any good."

Those desiring help in dealing with mental health problems often turn to persons other than treatment professionals. Persons of younger age, racial minorities, and lower SES groups (Briones et al. 1990; Husaini et al. 1994; Narikiyo \& Kameoka 1992) may prefer to obtain support from informal sources such as friends and family rather than professional sources. One study found that men did not want to be associated with the "types of people" that need therapy (Therapy in America, 2004). This suggests that even when persons with mental illness believe that professional treatment might help, they may still look elsewhere for assistance.

\section{Step 6: Deciding to Seek Professional Treatment}

Deciding that professional treatment is needed does not guarantee a subsequent decision to seek it. As at previous steps, many will delay at this point, hoping that the problem resolves on its own or as a result of self-help efforts.

The major issue at this step is deciding whether to seek care from a mental health specialist, a general medical provider, or from a provider in the "complementary and alternative medicines" sector (Kadushin, 1969). A substantial proportion of professional care for emotional disorders is administered by providers that are not mental health professionals (Kessler et al. 2005), and this appears to be strongly associated with negative attitudes toward mental health treatment (Mojtabai et al. 2002). For example, data from Australia's National Survey of Mental Health and Wellbeing indicates that general practitioners were the most commonly used providers of mental health services with $76 \%$ of those receiving mental health care using this type of service (Parslow \& Jorm, 2000). In the U.S general medical care is the most common treatment for the mental health problems for females, the elderly and the less educated (Mojtabai et al. 2002; Wang et al. 2006). Thus, although females are more likely than males to receive care for a mental illness, this difference appears to be primarily a result of a greater utilisation of general medical services than specialty mental health services (Kessler et al. 2001b).

Alternative treatment resources abound and might be determined to be preferable to seeing a professional mental health practitioner. The "voluntary support network" comprises self-help groups and other entities that many persons find helpful. Another resource is the clergy. Substantial 
numbers of persons with mental illness report that contact with their religious leaders comprises their only mental health treatment (Veroff et al. 1981b; Regier et al. 1993). Generally speaking, the effectiveness of the treatment provided by non-professionals and by clergy is unknown and in need of elucidation.

A related decision in regard to mental health problems is whether biologically oriented or psychologically oriented treatment is most appropriate (Wang et al. 2006). Not all persons with mental health problems who seek treatment resolve this issue, perhaps not realising it was a decision to be made (e.g. a client undergoes an intake with a psychologist but was intending to see a psychiatrist for the purpose of being prescribed medication). The type of treatment respondents prefer depends on their conception of the problem (Angermeyer et al. 2005). Seemingly ubiquitous promotional campaigns to convince the general public that all mental health problems are caused by biological dysregulation seem to be having an influence, as the treatment of mental illnesses is increasingly being administered in psychiatric and general medical settings (Kessler et al. 2005; Rosenthal et al. 2002). The effect of this promotional material on the treatment seeking process likely occurs at both this step and at step 2 . It is finally noted, however, that despite the relative paucity of endorsement, many persons report that psychotherapy rather than psychotropic medications is their first choice for mental health treatment (Riedel-Heller et al. 2005).

\section{Step 7: Seeking Treatment}

The final step in the process of seeking treatment for a mental health problem is the act of taking specific, tangible steps that lead to treatment, such as calling a clinic and scheduling an appointment. This step is completed when the person actually begins treatment (i.e. seeks the initial consultation). Of course, many would justifiably argue that "treatment" does not begin until the therapeutic contract is established and some potentially effective intervention is administered, but at this point the treatmentseeking process has ended.

There is a plethora of evidence that reaching this step in the process does not guarantee seeking treatment (e.g. Mojtabai et al. 2002). That is, research indicates that many persons recognise that a problem exists for which they could benefit from treatment, but nonetheless never seek it. For example, research suggests that patients schedule but then do not attend initial appointments at rates ranging from 20 to 60 percent (Nicholson, 1994). Delay and procrastination are common (Miller \& Saunders, 2007; Saunders, 1993) as the prospect of actually keeping an appointment with a mental health professional generates both self and social stigma (Corrigan 2004). Other major issues at this step, not confronted until now, concern treatment accessibility and affordability. These barriers are discussed in more detail in the following section. 


\section{Barriers Across the Process}

Research suggests that different barriers are more salient at different steps in the process of seeking treatment. Saunders and colleagues (2006) conceptualised treatment barriers as either "person-related" (cognitive or emotional) or "treatment-related" (availability or cost), and research suggests that person-related barriers tend to predominate throughout the treatment-seeking process.

With respect to problem recognition (step 1), lack of insight regarding impairment and lack of distress regarding the problem are primary barriers. The refusal or inability to acknowledge a problems existence makes further progress into the process of treatment seeking impossible. If a problem is recognized, however, the person-related barrier of stigma begins in various forms. Stigma generates shame when the person must decide that the problem is something internal (step 2), and shame encourages denial and minimization. Public attitudes toward persons with mental illness has begun to improve over the years (Bhugra, 1989; Skinner et al. 1995), but members of the public continue to fear persons with mental illness, blame them for their illnesses, and underestimate their chances of recovery (Corrigan et al. 2000; Levey \& Howells, 1994). Even mental health professionals display distancing and disparaging attitudes towards persons with mental illness (Servais \& Saunders, 2007).

Two other important person-related barriers concern alternatives to deciding change is necessary and actual change efforts. The expectation that a problem will "get better on its own" without a change in behaviour can also impede treatment seeking behaviour. Also, whereas most persons engage in self-help efforts (Saunders, 1993), often successfully (Tucker \& Gladsjo, 1993), research suggests that a preference for solving problems without treatment is a major factor in delaying or avoiding treatment irregardless of attitudes about its effectiveness (Cunningham 1993; Tucker 1995; West \& Saunders 2006).

The next step, admitting the need for treatment, is very difficult for many, and shame and stigma will lead many simply to refuse to acknowledge this. Research indicates that doubting the need for treatment seems to be a fairly universal person-related barrier (Fox et al. 2001; Hingson et al. 1982; Mojtabai et al. 2002). Ironically, the stigma of having a mental health problem can actually be exacerbated by seeking treatment for it (Corrigan 2004). Stigma related to negative attitudes towards treatment, treatment professionals, a self-image as a "person who needs treatment" are likely to be encountered later in treatment seeking. Fear of others' reactions may intensify, as one must publicly acknowledge a problem and the need for treatment (Corrigan 2004). Other salient barriers at this step are distrust of therapists and an unwillingness to view oneself as a person in need of therapy (Therapy in America, 2004). These attitudes decrease the chances that persons with mental illness will seek treatment (Corrigan 2004; Farina 1982), and there remains pressing need to improve "mental health literacy" aimed at reducing unnecessary suffering due to lack of treatment, inadequate treatment, or extensively delayed treatment for mental illness 
(Wright et al. 2005).

At the latter steps in the process, treatment-related barriers emerge, especially tangible obstacles to treatment such as inadequate availability of services (Allen 1995), the cost or the format of treatment (Snowden \& Thomas 2002), insurance problems, and other access issues (e.g. Brown et al. 2000; Fox et al. 1995; Tucker et al. 2004). For example, in a survey of over 1400 adolescents, Costello and colleagues (2007) found that only half of those with multiple mental illness diagnoses obtained treatment, but that rate was closer to one-in-ten if the youth did not have insurance. Similarly, Kessler and colleagues (2001a; see also Mojtabai et al. 2002) found that concerns about expense and uncertainty about where to go for treatment were common reasons for not seeking needed care for persons with mental illness. A lack of information regarding the availability or location of services, or a lack of understanding of which services would best meet their treatment needs can also interfere with obtaining treatment (Grant 1997; Tucker 1995). Overall, however, treatment-related barriers have consistently been shown to be less relevant to treatment seeking than person-related variables (e.g. Grant 1997; Miller \& Saunders 2007; however, see Costello et al 2007), and research suggests that treatment seeking is negotiated more quickly at the latter steps (Saunders 1993).

\section{The Influence of the Social Network}

Social support is a major influence on the process of seeking treatment. Kadushin (1969) asserted that consulting with others comprised a distinct step in the process, and he coined the term "friends and supporters of psychotherapy" to describe the positive attitude of the social network of persons who consult a mental health professional. Subsequent research has demonstrated that persons who seek "informal" help from their social network are more likely to seek formal or professional help (e.g. Adams et al. 2004; Knisely \& Northouse 1994), and also that consultation with one's social network is an aspect of the entire process, not a distinct step (e.g. Horwitz 1978; Saunders 1996). Both the persons who are consulted and the purpose of the consultation seem to change across the steps of the process.

\section{Social Support and Initial Treatment-Seeking Steps}

A person's intimate social network, which comprises spouses, family members and close friends, is predominantly important at the initial steps of problem identification and problem attribution (Gourash 1978; Kadushin 1969). The intimate social network can eliminate the need for formal help by reducing distress (Briones et al. 1990; Thoits 1985), but it also has the vital functions of providing feedback about impaired role functioning, encouraging attempts to address the problem, and encouraging realisation that formal help-seeking is warranted (Knisely \& Northouse 1994). 


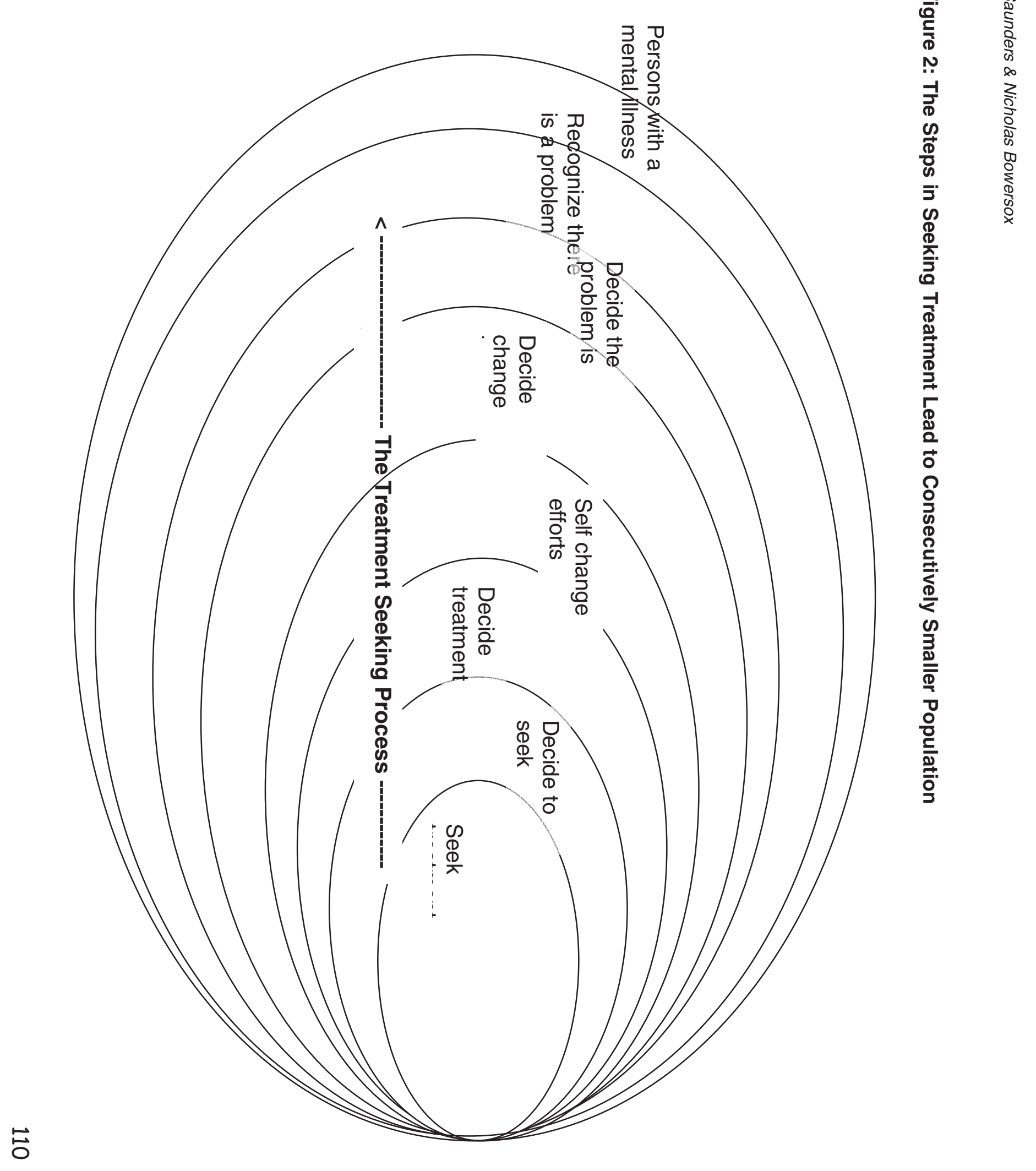


Non-intimate social network members, which includes co-workers, employers, and professionals that are not mental health specialists (such as clergy and primary care physicians), might also encourage treatment seeking by noting impairment-related concerns. For example, it is not uncommon for employers to coerce employees to take action to remediate dysfunction at work. Finally, primary care physicians may confront patients about the effects of a mental illness, such as a substance use disorder (Whitlock et al. 2004), although the capability of primary care doctors to recognize and effectively refer their patients with mental illness remains a concern (Mechanic 1990, 1997; Wells et al. 1996, 2000).

In contrast, intimate network members might discourage a person from admitting that a problem exists or, if a problem is undeniable, that it is due to mental illness. This is commonly seen in substance use problems, wherein the social network may have an investment in the person not admitting a problem and a need to stop using (e.g. Brennan et al. 1994). Research suggests that females in particular are encouraged to deny the existence of a substance use problem, which may help account for the greater likelihood that they will not seek treatment (Finkelstein 1993). The support for problem denial is also seen in other mental illnesses (Neighbors \& Jackson 1996; Snowden 1998; Vega et al. 2001; Zhang et al. 1998).

The social network may encourage a person to recognise that change is both necessary and possible (step three). At this point, the intimate network is still important, as this group has the largest investment in the person recovering from the problem (or the largest stake in seeing that the person does not change). They may suggest and encourage specific change strategies (step four) that have worked for them in similar situations. If effective, these strategies may make treatment seeking unnecessary. If ineffective, these suggestions may have the effect of delaying formal treatment seeking (Shin 2002). If the strategies (or the attitudes underlying them) are contradictory to seeking professional treatment, then the delay may be considerable or even permanent. Likewise, social networks can inhibit formal help-seeking by transmitting attitudes that discourage formal help-seeking (cf. George \& Tucker 1996; Ginsberg \& Brown 1982). If negative attitudes toward professional care are imparted or the severity of impairment associated with the problem is invalidated, professional help-seeking is less likely.

\section{Social Support and Later Treatment-Seeking Steps}

The intimate support network may also provide information about the utility and availability of professional resources (step five) and exert pressure on the individual to decide to seek treatment (step six) (Room 1989), but research suggests that non-intimate support sources become more important at these latter steps (Saunders 1996). At the point of deciding which treatment would be most appropriate, consultation with professionals such as medical doctors, attorneys, and clergy becomes much more common. For example, clergy are commonly consulted during-and are occasionally the end-point of-the treatment seeking process (Regier et al. 1993). There has historically been little cooperation between clergy and mental health care providers, 
partly related to lack of mutual respect and the perceived lack of shared values (Neeleman \& Persaud 1995), but clergy are an essential aspect of treatment seeking.

\section{Variations of the Process}

This proposed sequence of steps in the treatment-seeking process is based on an analysis of the literature, but it does not describe all persons who obtain care from a mental health professional. Many persons enter treatment uncertain of what a mental illness is and unconvinced that their problem is due to mental health issues. They may have been coerced by the judicial system, by spouses and loved ones, or by employers. It is often necessary to educate persons seeking care regarding the nature of their problems, since they cannot effectively engage in care unless they agree about the problem and its potential solution. Effective interventions, such as motivational interviewing, that explicitly intervene with such issues have been developed (Miller \& Rollnick 1991). In other words, a person may obtain treatment for a mental illness without accomplishing these initial steps, although they must eventually be achieved prior to the commencement of effective treatment. There is currently insufficient research regarding how many persons enter treatment uncertain about whether the problem is due to mental illness.

The process of seeking treatment might best be understood as recursive rather than directly linear. Patients may need to revisit steps and decisions repeatedly. Likewise, it should be emphasized that the steps are closely related. The high no-show rate at initial appointments suggests that many persons navigate all of the steps in the process but do not terminate the process by entering treatment. Not attending a scheduled consultation is associated with harbouring doubts about the seriousness of the problem (Scott \& Pope 2002) but also to the chronicity of the problem, which might cause doubts about the effectiveness of treatment (Nicholson 1994). Sparks, Daniels and Johnson (2003) found that persons who referred themselves to treatment were less likely not to attend the first scheduled appointment than persons referred by others, suggesting that early process decisions (i.e. that a problem does exist and that treatment will help) affects later decisions (to seek treatment). Similarly, patients may "complete" the treatment-seeking process yet remain ambivalent about the idea that they have a mental illness. Such persons may leave the treatment seeking process altogether, but many simply revisit prior steps.

\section{Implications for Improving Access}

Research into why some individuals seek treatment for mental health problems whereas others do not would be improved by focusing on treatment seeking as a process. It is simplistic and misleading to say that persons with mental health problems either do or do not seek treatment. More accurately, they must be understood to be at various steps of the treatment seeking process. Each step in the process is unique, with different possible alternative decision, barriers, and social support. At the same time, the steps are interrelated. Thus someone may seek treatment (accomplish all of the steps) and be prescribed a treatment regimen, but may refuse to adhere to it related to the idea that the 
problem is not mental health related or cannot be successfully treated (early steps in the process).

Distinguishing these steps allows research findings to be placed into proper context. For example, it has been shown repeatedly that certain populations (e.g. ethnic and racial minorities) are more vulnerable to mental health problems but are less likely to receive mental heath services (e.g. Clark et al. 1999; Fox et al. 1995; Goldstein et al. 2006; Matsuoka et al. 1997; Swartz et al. 1998). Some potential reasons for this finding include less understanding about mental illness and its symptoms and greater reluctance to admit psychological symptoms, which are early process decisions, but also negative attitudes towards treatment and fear of being stigmatised, which are later process issues (Bussing et al. 1998; Snowden 1996; Sussman et al. 1987; Zylstra \& Steitz 1999).

Attempts to redress barriers and improve access can be more precisely focused with an awareness of the process. Improving understanding of the symptoms and associated consequences of mental illness focuses on a different aspect of the process than and encouraging people to realize that treatment is effective. Likewise, encouraging people to overcome denial is an early process intervention, whereas making treatments more accessible and affordable is a latter process intervention. In similar regard, research suggests that efforts to improve access will be limited in success if they do not address the entire process. Promoting the effectiveness of various interventions is unlikely to work with a person who refuses to acknowledge that a problem exists, for example. Likewise, assisting someone overcome denial (e.g. confronting a drinker about the negative consequences to his physical health) is unlikely to lead to treatment seeking if the person believes that change must be self-directed or does not believe treatment would be effective.

Finally, understanding it as a process enhances efforts to utilise the social network to encourage treatment seeking. Intimate social network members are most important at early steps, when the person needs to recognize that a problem exists and that change is needed. Non-intimate social network members, such as clergy and primary care providers, need to be aware of their role at the latter steps in the process, when accurate information about treatment effectiveness, options and resources are needed. 


\section{References}

Adams, M., Ford, J. \& Dailey, W. 2004. Predictors of help seeking among Connecticut adults after September 11: 2001. American Journal of Public Health 94: 1596-1602.

Alegria, M., Canino, G., Rios, R., Vera, M., Calderon, J., Rusch, D. \& Ortega, A. 2002. Mental health care for Latinos: Inequalities in use of specialty mental health services among Latinos, African Americans, and non-Latino Whites. Psychiatric Services 53: 1547-1555.

Allen, K. 1995. Barriers to treatment for addicted African-American women. Journal of the National Medical Association 87: 751-756.

Alvidrez, J. 1999. Ethnic variations in mental health attitudes and service use among low-income African American, Latina, and European American young women. Community Mental Health Journal 35: 515-530.

Anatchkova, M., Velicer, W. \& Prochaska, J. 2006. Replication of subtypes for smoking cessation with the preparation stage of change. Addictive Behaviours 31: 1101-1115.

Angermeyer, M., Breier, P., Dietrich, S., Kenzine, D. \& Matschinger, H. 2005. Public attitudes toward psychiatric treatment: An international comparison. Social Psychiatry \& Psychiatric Epidemiology 40: 855-64.

Baxter, J., Kokaua, J., Wells, J., McGee, M., Oakley-Browne, M. \& the New Zealand Mental Health Survey Research Team. 2006. Ethnic comparisons of the 12-month prevalence of mental disorders and treatment contact in Te Rau Hinengaro: The New Zealand Mental Health Survey. Australian and New Zealand Journal of Psychiatry 40: 905-913.

Bell, D., Montoya, I., Richard, A. \& Dayton, C. 1998. The motivation for drugabuse treatment: testing cognitive and 12-step theories. American Journal of Drug \& Alcohol Abuse 24: 551-571.

Bhugra, D. 1989. Attitudes towards mental illness. Acta Psychiatrica Scandinavica 80: 1-12.

Borges, G., Medina-Mora, M., Wang, P., Lara, C., Berglund, P. \& Walters, E. 2006. Treatment and adequacy of treatment of mental disorders among respondents to the Mexico national comorbidity survey. American Journal of Psychiatry 163: 1371-1378

Brennan, P., Moos, R. \& Mertens, J. 1994. Personal and environmental risk factors as predictors of alcohol use, depression, and treatment-seeking: A longitudinal analysis of late-life problem drinkers. Journal of Substance Abuse 6: 191-208.

Briones, D., Heller, P: Chalfant, H., Roberts, A., Aguirre-Hauchbaum, S. \& Farr, W. 1990. Socio-economic status, ethnicity, psychological distress, and 
readiness to utilize a mental health facility. American Journal of Psychiatry 147: $1333-1340$.

Brockington, I., Hall, P., Levings, J. \& Murphy, C. 1993. The community's tolerance of the mentally ill. British Journal of Psychiatry 162: 93-99.

Brown, E., Ojeda, V., Wyn, R. \& Levan, R. 2000. Racial and Ethnic Disparities in Access to Health Insurance and Health Care. Los Angeles, UCLA Center for Health Policy Research and The Henry J. Kaiser Family Foundation.

Bussing, R., Schoenberg, N., Rogers, K., Zima, B. \& Angus, S. 1998. Explanatory models of ADHD: Do they differ by ethnicity, child gender, or treatment status? Journal of Emotional and Behavioural Disorders 6: 233-242.

Carlton, P. \& Deane, F. 2000. Impact of attitudes and suicidal ideation on adolescents' intentions to seek professional psychological help. Journal of Adolescence 23: 35-45.

Christiana J., Gilman, S., Guardino, M., Mickelson, K., Morselli, P., Olfson, M. \& Kessler, R. 2000. Duration between onset and time of obtaining initial treatment among people with anxiety and mood disorders: An international survey of members of mental health patient advocate groups. Psychological Medicine 30: 693-703.

Ciarrochi, J., Wilson, C., Deane, F. \& Rickwood, D. 2003. Do difficulties with emotions inhibit help-seeking in adolescence? The role of age and emotional competence in predicting help-seeking intentions. Counselling Psychology Quarterly 16: 103-120.

Clark, R., Anderson, N., Clark, V. \& Williams, D. 1999. Racism as a stressor for African Americans. American Psychologist 54: 805-816.

Cooper, A., Corrigan, P. \& Watson, A. 2003. Mental illness stigma and care seeking. Journal of Nervous and Mental Disease 191: 339 -341.

Corrigan, P. 2004. How stigma interferes with mental health care. American Psychologist 59: 614-625.

Corrigan, P., River, L., Lundin, R., Uphoff Wasowski, K., Campion, J., Mathisen, J., Goldstein, H., Bergman, M., Gagnon, C. \& Kubiak, M. 2000. Stigmatizing attributions about mental illness. Journal of Community Psychology 28: 91-102.

Costello, E., Copeland, W., Cowell, A. \& Keeler, G. 2007. Service costs of caring for adolescents with mental illness in a rural community, 1993-2000. American Journal of Psychiatry 164, 36-42.

Cunningham, J., Sobell, L., Sobell, M., Agrawal, S. \& Toneatto, T. 1993. Barriers to treatment: Why alcohol and drug abusers delay or never seek treatment. Addictive Behaviours 18: 347-353. 
Farina, A. 1982. The stigma of mental disorder. In Miller, A. In the Eye of the Beholder (pp.305-363). New York, Praeger.

Finkelstein, N. 1993. Treatment programming for alcohol and drug dependent pregnant women. International Journal of Addictions 28: 1275-1310.

Fox, J., Merwin, E. \& Blank, M. 1995. Defacto mental health services in the rural South. Journal of Health Care for the Poor and Underserved 6: 434-68.

Fox, J., Blank, M., Rovnyak, V. \& Barnett, R. 2001. Barriers to help seeking for mental disorders in a rural impoverished population. Community Mental Health Journal 37: 421-436.

George, A. \& Tucker, J. 1996. Help-seeking for alcohol-related problems: Social contexts surrounding entry into alcoholism treatment or alcoholics anonymous. Journal of Studies on Alcohol 57: 449-457.

Ginsberg, S. \& Brown, G. 1982. No time for depression: A study of helpseeking among mothers of preschool children. In Mechanic, D. Symptoms, Illness Behaviour, and Help-seeking. New York, Prodist.

Goldstein, R., Olfson, M., Wickramaratne, P. \& Wolk, S. 2006. Use of outpatient mental health services by depressed and anxious children as they grow up. Psychiatric Services 57: 966 - 975.

Gourash, N. 1978. Help-seeking: A review of the literature. American Journal of Community Psychology 6: 413-423.

Grant, B. 1997. Barriers to alcoholism treatment: reasons for not seeking treatment in a general population sample. Journal of Studies on Alcohol 58: 365-371.

Hajema, K., Knibbe, R. \& Drop, M. 1999. Social resources and alcohol-related losses as predictors of help seeking among male problem drinkers. Journal of Studies on Alcohol 60: 120-129.

Hamre, P., Dahl, A. \& Malt, U. 1994. Public attitudes to the quality of psychiatric treatment, psychiatric patients, and prevalence of mental disorders. Nordic Journal of Psychiatry 48: 275-281.

Hingson, R., Mangione, T., Meyers, A. \& Scotch, N. 1982. Seeking help for alcohol problems: A study in the Boston metropolitan area. Journal of Studies on Alcohol 43: 273-288.

Horwitz, A. 1978. Family, kin and friend networks in psychiatric help-seeking. Social Science and Medicine 12: $297-304$.

Husaini, B., Moore, S. \& Cain, V. 1994. Psychiatric symptoms and helpseeking behaviour among the elderly: An analysis of racial and gender 
differences. Journal of Gerontological Social Work 21: 177-196.

Israelashvili, M. 1999. Adolescents help-seeking behaviour in times of community crisis. International Journal for the Advancement of Counselling 21: 87-96.

Jorgensen, P. 1995. Recovery and insight in schizophrenia. Acta Psychiatrica Scandinavica 92: 436-40.

Kadushin, C. 1969. Why People go to Psychiatrists. New York. Atherton.

Kaskutas, L., Weisner, C. \& Caetano, R. 1997. Predictors of help-seeking among a longitudinal sample of the general population, 1984-1992. Journal of Studies on Alcohol 58: 155-161.

Kawakami, N: Takeshima, T., Ono, Y., Uda, H., Hata, Y., Nakane, Y., Nakane, H., Iwata, N., Furukawa, T. \& Kikkawa, T. 2005. Twelve-month Prevalence, Severity, and Treatment of Common Mental Disorders in Communities in Japan: Preliminary Finding from the World Mental Health Japan Survey 20022003. Psychiatry and Clinical Neuroscience 59: 441-452.

Kessler, R., Demler, O., Frank, R., Olfson, M., Pincus, H., Walters, E., Wang, P., Wells, K. \& Zaslavsky, A. 2005. Prevalence and Treatment of Mental Disorders, 1990 to 2003. New England Journal of Medicine 352: 2515-2523.

Kessler, R., Berglund, P., Bruce, M., Koch, J., Laska, E., Leaf, P., Manderscheid, R., Rosenheck, R., Walters, E. \& Wang, P. 2001. The Prevalence and Correlates of Untreated Serious Mental IIIness. Health Services Research 36: 987-1007.

Kessler, R., Soukup, J., Davis, R., Foster, D., Wilkey, S., Rompay, M. \& Eisenberg, D. 2001. The use of complementary and alternative therapies to treat anxiety and depression in the United States. American Journal of Psychiatry 158: 289-294.

Kessler, R., Olfson, M. \& Berglund, P. 1998. Patterns and predictors of treatment contact after first onset of psychiatric disorders. American Journal of Psychiatry 155: 62-69.

Kessler, R., Reuter, J. \& Greenley, J. 1979. Sex differences in the use of psychiatric outpatient facilities. Social Forces 58: 557-571.

Kessler, R., Chiu, W., Demler, O., Merikangas, K. \& Walters, E. 2005. Prevalence, severity, and comorbidity of twelve-month DSM-IV disorders in the National Comorbidity Survey Replication (NCS-R). Archives of General Psychiatry 62: 617-627.

King, M. \& Tucker, J. 1998. Natural resolution of alcohol problems without treatment: environmental contexts surrounding the initiation and maintenance of stable abstinence or moderation drinking. Addictive Behaviours 23: 537541. 
Knisely, J. \& Northouse, L. 1994. The relationship between social support, help-seeking behaviour, and psychological distress in psychiatric clients. Archives of Psychiatric Nursing 8: 357-365.

Leaf, P., Bruce, M. \& Tischler, G. 1986. The differential effect of attitudes on the use of mental health services. Social Psychiatry 21: 187-192.

Levey, S. \& Howells, K. 1994. Accounting for the fear of schizophrenia. Journal of Community and Applied Social Psychology 4: 313-328.

Lim, D., Sanderson, K. \& Andrews, G. 2000. Lost productivity among full-time workers with mental disorders. The Journal of Mental Health Policy and Economics 3, 139-146.

Link, B., Phelan, J., Bresnahan, M., Stueve, A. \& Pescosolido, B. 1999. Public conceptions of mental illness: Labels, causes, dangerousness, and social distance. American Journal of Public Health 89: 1328 -1333.

Matsuoka, J., Breaux, C. \& Ryujin, D. 1997. National utilization of mental health services by Asian Americans/Pacific Islanders. Journal of Community Psychology 25: 141-146.

Mechanic, D. 1990. Treating mental illness: Generalist vs. specialist. Health Affairs 9: 61-76.

Mechanic, D. 1997. Approaches for coordinating primary and specialty care for persons with mental illness. General Hospital Psychiatry 19: 395-402.

Mechanic, D, McAlpine, D., Rosenfield, S. \& Davis, D. 1994. Effects of Illness attribution and depression on the quality of life among persons with serious mental illness. Social Science and Medicine 39: 155-64.

Meile, R. \& Whitt, H. 1981. Cultural consensus and definition of mental illness. Social Science and Medicine Part A: Medical Sociology 15: 231-242.

Meltzer, H., Bebbington, P., Brugha, T., Farrell, M., Jenkins, R. \& Lewis, G. 2003. The reluctance to seek treatment for neurotic disorders. International Review of Psychiatry 15: 123-128.

Miller, W. \& Rollnick, S. 1991. Motivational interviewing: Preparing people to change addictive behaviour. New York, Guilford Press.

Miller, M. \& Saunders, S. (2007, May). Barriers to Alcohol Treatment: Analyses of the NESARC Data Set. Paper presented to the Midwestern Psychological Association Annual Meeting, Chicago, Illinois, USA.

Mojtabai, R., Olfson, M. \& Mechanic, D. 2002. Perceived need and helpseeking in adults with mood, anxiety, or substance use disorders. Archives of General Psychiatry 59: 77-84. 
Naganuma,Y., Tachimori, H., Kawakami, N., Takeshima, T., Ono, Y., Uda, H., Hata, Y., Nakane, Y., Nakane, H., Iwata, N., Furukawa, T. \& Kikkawa, T. 2006. Twelve-month use of mental health services in four areas in Japan: Findings from the World Mental Health Japan Survey 2002-2003. Psychiatry and Clinical Neuroscience 60: 240-8.

Narikiyo, T. \& Kameoka, V. 1992. Attributions of mental illness and judgments about help seeking among Japanese-American and White American students. Journal of Counseling Psychology 39: 363-369.

Neeleman, J. \& Persaud, R. 1995. Why do psychiatrists neglect religion? British Journal of Medical Psychology 68: 169-178.

Neighbors, H. \& Jackson, J. (Eds.) 1996. Mental Health in Black America. Thousand Oaks, CA, Sage.

Nicholson, I. 1994. Factors involved in failure to keep initial appointments with mental health professionals. Hospital and Community Psychiatry 45:276-278.

Ortega, A. \& Alegria, M. 2002. Self-reliance, mental health need, and the use of mental healthcare among island Puerto Ricans. Mental Health Services Research 4: 131-140.

Parslow, R. \& Jorm, A. 2000. Who uses mental health services in Australia? An analysis of data from the National Survey of Mental Health and Wellbeing. Australian and New Zealand Journal of Psychiatry 34: 997-1008.

Proudfoot, H. \& Teesson, M. 2002. Who seeks treatment for alcohol dependence? Findings from the Australian National Survey of Mental Health and Wellbeing. Social Psychiatry and Psychiatric Epidemiology 37: 451-456.

Regier, D., Narrow, W., Rae, D., Manderscheid, R., Locke, B. \& Goodwin, F. 1993. The De Facto US Mental Health and Addictive Disorders Service System: Epidemiologic catchment area prospective 1-year prevalence rates of disorders and services. Archives of General Psychiatry 50:85-94.

Riedel-Heller, S., Matschinger, H. \& Angermeyer, M. 2005. Mental disorders-who and what might help? Help-seeking and treatment preferences of the lay public. Social Psychiatry and Psychiatric Epidemiology 40: 167-174.

Room, R. 1989. The U.S. general populations experiences of responses to alcohol problems. British Journal of Addiction 84: 1291-1304.

Rosenthal, M., Berndt, E., Donohue, J., Frank, R. \& Epstein, A. 2002. Promotion of prescription drugs to consumers. New England Journal of Medicine 346: 498-505.

Saravanan, B., Jacob, K., Johnson, S., Prince, M., Bhugra, D. \& David, A. 2007. Assessing insight in schizophrenia: East meets West. British Journal of Psychiatry 190:243-247. 
Saunders, S. 1993. Applicants' experience of the process of seeking therapy. Psychotherapy 30: 554-564.

Saunders, S. 1996. Applicants' experience of social support in the process of seeking psychotherapy. Psychotherapy 33: 617-627.

Saunders, S., Resnick, M., Hoberman, H. \& Blum, R. 1994. Formal helpseeking behaviour of adolescents identifying themselves as having mental health problems. Journal of the American Academy of Child and Adolescent Psychiatry 33: 718-728.

Saunders, S., Zygowicz, K. \& D'Angelo, B. 2006. Person-related and treatment-related barriers to alcohol treatment. Journal of Substance Abuse Treatment 30: 261-270.

Scott, J. \& Pope, M. 2002. Nonadherence with mood stabilizers: Prevalence and predictors. Journal of Clinical Psychiatry 63, 384-390.

Servais, L. \& Saunders, S. 2007. Clinical psychologists perceptions of persons with mental illness. Professional Psychology: Research \& Practice 38, 214219.

Sheets, J., Prevost, J. \& Reihman, J. 1982. Young adult chronic patients: Three hypothesized subgroups. Hospital \& Community Psychiatry 33: 197203.

Shin J. 2002. Help-seeking behaviour by Korean immigrants for depression. Issues in Mental Health Nursing 23: 461-476,

Sirey, J., Bruce, M., Alexopoulos, G., Perlick, D., Friedman, S. \& Meyers, B. 2001. Stigma as a barrier to recovery: Perceived stigma and patient-rated severity of illness as predictors of antidepressant drug adherence. Psychiatric Services 52: 1615-1620.

Skinner, L., Berry, K., Griffith, S. \& Byers, B. 1995. Generalizability and specificity of the stigma associated with the mental illness label: A reconsideration twenty-five years later. Journal of Community Psychology 23: 3-17.

Smedley, B., Stith, A. \& Nelson, A. (Eds) 2003. Unequal treatment: confronting racial and ethnic disparities in health care. Washington, D.C.,National Academy Press.

Snowden, L. 1998. Racial differences in informal help seeking for mental health problems. Journal of Community Psychology 26: 429 - 438

Snowden, L. 1996. Using client information to improve mental health and substance abuse outcomes. In Steinwachs, D., Flynn, L., Norquist, G., \& Skinner E. (Eds.) New Directions for Mental Health Services, 71. San Francisco, Jossey-Bass. 
Snowden, L. \& Thomas, K. 2000. Medicaid and African American outpatient mental health treatment. Mental Health Services Research 2: 115-120.

Solomon, Z. 1989. Untreated combat-related PTSD - Why some Israeli veterans do not seek help. Israeli Journal of Psychiatry \& Related Sciences 26: 111-123.

Sparks, W. A., Daniels, J. A. \& Johnson, E. 2003. Relationship of referral source, race, and wait time on pre-intake attrition. Professional Psychology: Research and Practice 34: 514-518.

Stice, E., Burton, E., Bearman, S. \& Rohde, P. 2007. Randomised trial of a brief depression prevention programme: An elusive search for a psychosocial placebo control condition. Behaviour Research \& Therapy 45: 863-876.

Sussman, L., Robins, L. \& Earls, F. 1987. Treatment-seeking for depression by Black and White Americans. Social Science and Medicine 24: 187-196.

Swartz, M., Wagner, H., Swanson, J., Burns, B., George, L. \& Padgett, D. 1998. Comparing use of public and private mental health services: The enduring barriers of race and age. Community Mental Health Journal 34: 133144.

Therapy in America, 2004. 2004. Therapy In America: Conducted by Harris Interactive on Behalf of Psychology Today and PacifiCare Behavioural Health. Retrieved May 1, 2007, from

http://psychologytoday.com/pto/topline report 042904.pdf.

Thoits, P. 1986. Social support as coping assistance. Journal of Consulting \& Clinical Psychology 54: 416-423.

Tucker, J. 1995. Predictors of help-seeking and the temporal relationship of help to recovery among treated and untreated recovered problem drinkers. Addiction 90: 805-809.

Tucker, J. \& Gladsjo, J. 1993. Help-seeking and recovery by problem drinkers: Characteristics of drinkers who attended alcoholics anonymous or formal treatment or who recovered without assistance. Addictive Behaviours 18: 529542.

Tucker, J., Vuchinich, R. \& Gladsjo, J. 1994. Environmental events surrounding natural recovery from alcohol-related problems. Journal of Studies in Alcohol 55: 401-11.

Tucker, J., Vuchinich, R. \& Rippens, P. 2004. A factor analytic study of influences on patterns of help-seeking among treated and untreated alcohol dependent persons. Journal of Substance Abuse Treatment 26: 237-242.

Vega, W., Kolody, B. \& Aguilar-Gaxiola, S. 2001. Help seeking for mental health problems among Mexican Americans. Journal of Immigrant Health 3: 133-140. 
Veroff, J., Douvan, E. \& Kulka, R. 1981a. The Inner-American: A Self-Portrait from 1957 to 1976. New York, Basic Books.

Veroff, J., Kulka, R. \& Douvan, E. 1981b. Mental Health in America: Patterns of Help-seeking from 1957 to 1976. New York, Basic Books.

Wang, P., Demler, O., Olfson, M., Pincus, H., Wells, K. \& Kessler, R. 2006. Changing profiles of service sectors used for mental health care in the United States. American Journal of Psychiatry. 163: 1187-1198.

Wang, P., Lane, M., Kessler, R., Olfson, M., Pincus, H. \& Wells, K. 2005. Twelve-month use of mental health services in the U.S.: Results from the National Comorbidity Survey Replication (NCS-R). Archives of General Psychiatry 62: 629-640.

Weiner, B., Magnusson, J. \& Perry, R. 1988. An attributional analysis of reactions to stigmas. Journal of Personality \& Social Psychology 55: $738-748$. Wells,

K., Manning, W. \& Benjamin, B. 1986. A comparison of the effects of sociodemographic factors and health status on use of outpatient mental health services in HMO and fee-for-service plans. Medical Care 24: 949-960

Wells, K., Sherbourne, C., Schoenbaum, M., Duan, N., Meredith, L., Unutzer, J., Miranda, J., Carney, M. \& Rubenstein, L. 2000. Impact of disseminating quality improvement programs for depression in managed primary care: A randomised controlled trial. Journal of the American Medical Association 283:212-20.

Whitlock, E., Polen, M. \& Green, C. 2004. Behavioural counselling interventions in primary care to reduce risky/harmful alcohol use by adults: Summary of the evidence for the U.S. Preventive Services Task Force. Annals of Internal Medicine 140: 558-569.

Whitt, H. \& Meile, R. 1985. Alignment, magnification and snowballing processes in the definition of symptoms of mental illness. Social Forces 63: 682-697.

Williams, J. 1998. Competing demands: Does care for depression fit in primary care? Journal of General Internal Medicine 13: 137-139.

World Health Organisation. 2004. WHO Mental Health Survey Consortium, Prevalence, severity, and unmet need for treatment of mental disorders in the World Health Organization World Mental Health Surveys Journal of American Medical Association 291: 2581-2590.

Wright, A., Harris, M., Wiggers, J., Jorm, A., Cotton, S., Harrigan, S., Hurworth, R. \& McGorry, P. 2005. Recognition of depression and psychosis by young Australians and their beliefs about treatment. Medical Journal of Australia 183: 18-23. 
Zhang, A., Snowden, L. \& Sue, S. 1998. Differences between Asian and White Americans Help-seeking and utilization patterns in the Los Angeles area. Journal of Community Psychology 26: 317-326.

Zylstra, R. \& Steitz, J. 1999. Public knowledge of late-life depression and ageing. Journal of Applied Gerontology 18: 63-76. 
